\title{
Produto educacional: a materialidade de um simpósio do currículo integrado
}

\author{
Educational product: the materiality of an integrated curriculum symposium \\ Producto educativo: la materialidad de un simposio curricular integrado
}

Recebido: 26/10/2021 | Revisado: 04/11/2021 | Aceito: 12/11/2021 | Publicado: 22/11/2021

Lílian Gobbi Dutra Medeiros

ORCID: https://orcid.org/0000-0001-6783-3101

Instituto Federal de Educação, Ciência e Tecnologia Goiano, Brasil

E-mail: liliandutra@iftm.edu.br

Márcia de Souza Oliveira Paes Leme Alberto

ORCID: https://orcid.org/0000-0003-4666-6732

Instituto Federal de Educação, Ciência e Tecnologia Goiano, Brasil

E-mail: marciapaes@iftm.edu.br

Marco Antônio de Carvalho

ORCID: https://orcid.org/0000-0002-5127-5886

Instituto Federal de Educação, Ciência e Tecnologia Goiano, Brasil

E-mail: marco.carvalho@ifgoiano.edu.br

Léia Adriana da Silva Santiago

ORCID: https://orcid.org/0000-0002-6057-6808

Instituto Federal de Educação, Ciência e Tecnologia Goiano, Brasil

E-mail: leia.adriana@ifgoiano.edu.br

\begin{abstract}
Resumo
Os programas de mestrado e doutorado profissionais têm como foco a proposta de um produto educacional. O presente artigo visa apresentar os passos para o planejamento, desenvolvimento e a avaliação de um produto educacional na área do currículo integrado, aplicado no Instituto Federal do Triângulo Mineiro - Campus Ituiutaba. O trabalho, que foi fruto de uma pesquisa de mestrado, foi do tipo exploratório e envolveu pesquisa de campo, com pesquisa bibliográfica e uso do grupo focal para a coleta de dados, cujos resultados foram analisados qualitativamente. A partir dos conceitos de interdisciplinaridade, currículo integrado e formação humana integral e apoiados nos três eixos temáticos de Kaplún para a criação de materiais educativos, desenvolvemos um simpósio, buscando contribuir para a discussão e para a formação continuada dos professores, disseminando conhecimento sobre o tema do currículo integrado para toda a comunidade escolar. A partir da avaliação do produto educacional, entendemos que a realização do simpósio trouxe benefícios à comunidade acadêmica, que participou de momentos de formação, discussão e troca de experiências práticas sobre o currículo integrado.
\end{abstract}

Palavras-chave: Produto educacional; ProfEPT; Currículo integrado; Ensino médio integrado; Institutos Federais.

\begin{abstract}
Professional master's and doctoral programs are focused on the proposal of an educational product. This article aims to present the steps for planning, developing and evaluating an educational product in the area of integrated curriculum, applied at the Federal Institute of Triângulo Mineiro - Ituiutaba Campus. This work, which was the result of a master's research, was exploratory and involved field research, with bibliographical research and use of the focus group for data collection, whose results were analyzed qualitatively. Based on the concepts of interdisciplinarity, integrated curriculum and integral human training and supported by Kaplún's three thematic axes for the creation of educational materials, we developed a symposium, seeking to contribute to the discussion and continuing education of teachers, disseminating knowledge on the topic of the integrated curriculum for the entire school community. From the evaluation of the educational product, we understand that the symposium brought benefits to the academic community, which took part in moments of training, discussion and exchange of practical experiences about the integrated curriculum.
\end{abstract}

Keywords: Educational product; ProfEPT; Integrated curriculum; Integrated high school; Federal Institutes.

\section{Resumen}

Los programas profesionales de maestría y doctorado se enfocan en la propuesta de un producto educativo. Este artículo tiene como objetivo presentar los pasos para la planificación, desarrollo y evaluación de un producto educativo en el área del currículo integrado, aplicado en el Instituto Federal del Triângulo Mineiro - Campus Ituiutaba. El trabajo, que fue resultado de una investigación de maestría, fue exploratoria e involucró investigación de campo, con búsqueda bibliográfica y uso del grupo focal para la recolección de datos, cuyos resultados fueron analizados cualitativamente. A partir de los conceptos de interdisciplinariedad, currículo integrado y formación humana integral y apoyados en los tres ejes temáticos de Kaplún para la creación de materiales educativos, desarrollamos un simposio buscando contribuir a la discusión y formación continua de los docentes, difundiendo conocimientos sobre el tema del curriculo integrado para 
toda la comunidad escolar. A partir de la evaluación del producto educativo, entendemos que el simposio trajo beneficios a la comunidad académica, que participó en momentos de formación, discusión e intercambio de experiencias prácticas sobre el currículo integrado.

Palabras clave: Producto educativo; ProfEPT; Currículo integrado; Escuela secundaria integrada; Institutos Federales.

\section{Introdução}

Nos últimos anos, os programas de pós-graduação profissionais têm ganhado cada vez mais espaço. Na área de Ensino, por exemplo, que foi uma das pioneiras na oferta de cursos de Mestrado Profissional, esses “[...] já representam aproximadamente $52 \%$ [...]" (Rizzatti et al., 2020) da área. Os programas de mestrado e doutorado profissionais têm como foco o desenvolvimento de produtos educacionais (PE), que devem ser aplicados em situações reais de ensino, visando contribuições para a prática profissional. Considerando que um dos objetivos desses programas é "transferir conhecimento para a sociedade de forma a atender às demandas sociais e econômicas, com vistas ao desenvolvimento nacional, regional e local” (Capes, 2019, n.p.), os PEs podem ser um caminho para o cumprimento desse objetivo. Sobretudo na área de Ensino e Educação, é bastante comum encontrar propostas de materiais textuais, como sequências didáticas, guias, manuais, aplicativos e cartilhas. Pouco é feito, no entanto, quanto à realização de eventos, por exemplo.

Nesse sentido, o presente artigo visa apresentar os passos para o planejamento, desenvolvimento e a avaliação de um PE na área do currículo integrado, no formato de um simpósio, realizado no Instituto Federal do Triângulo Mineiro (IFTM) Campus Ituiutaba. O produto foi fruto de uma pesquisa no programa do Mestrado Profissional em Educação Profissional e Tecnológica (ProfEPT) do Instituto Federal de Educação, Ciência e Tecnologia Goiano (IF Goiano). A pesquisa que precedeu a elaboração do PE se baseou nos conceitos de interdisciplinaridade, currículo integrado e formação humana integral, apoiada em autores como Ciavatta (2014), Moura (2012, 2013) e Ramos (2005, 2008).

Assim como é da natureza dos PEs, caminhamos na tentativa de “[...] enriquecer a prática pedagógica dos professores [...]" (Soares et al., 2021) e contribuir para a materialização do currículo integrado no campus. No entanto, conforme aprendemos com Freire e Faundez (1985), é preciso perguntar, e não trazer respostas. Partindo da cotidianeidade, sendo esta uma postura crítica que nos permite compreender o cotidiano em que estamos inseridos, precisamos, primeiramente, aprender a perguntar. Dessa maneira, ao pensar no produto educacional aqui apresentado, elaboramos a seguinte problematização: como contribuir para a integração curricular no IFTM Campus Ituiutaba, considerando as demandas existentes? Por isso, conforme detalharemos mais adiante, partimos das necessidades colocadas pelos próprios professores, desenvolvendo um produto sob a perspectiva dos eixos temáticos de Kaplún (2003), com vistas a contribuir para a discussão e para a formação continuada dos professores, disseminando conhecimento sobre o tema do currículo integrado para toda a comunidade escolar. O estudo, do tipo exploratório, foi realizado a partir de pesquisa de campo, com pesquisa bibliográfica e uso do grupo focal para a coleta de dados, cujos resultados foram analisados por meio de abordagem qualitativa.

Nesse sentido, passamos a apresentar, nas linhas seguintes, o desenvolvimento do PE, caminhando, inicialmente, pelos procedimentos metodológicos deste estudo. Depois, traremos os conceitos que balizaram a pesquisa. Na sequência, faremos a descrição dos passos teórico-metodológicos que seguimos para pensar e realizar o PE, bem como dos resultados observados. Traremos também a análise da avaliação do produto e, por fim, nossas considerações finais.

\section{Procedimentos Metodológicos}

A investigação foi do tipo exploratória (Gil, 2008), com pesquisa de campo, e os resultados foram analisados qualitativamente. A escolha dessa abordagem se deu pelo fato de que a pesquisa qualitativa apresenta uma série de contribuições: 
1) A incorporação, entre os pesquisadores em Educação, de posturas investigativas mais flexíveis e com maior adequação para estudos de processos micro-sócio-psicológicos e culturais, permitindo iluminar aspectos e processos que permaneciam ocultados pelos estudos quantitativos. 2) A constatação de que, para compreender e interpretar grande parte das questões e problemas da área de Educação, é preciso recorrer a enfoques multi/inter/transdiciplinares e a tratamentos multidimensionais. 3) A retomada do foco sobre os atores em educação, ou seja, os pesquisadores procuram retratar o ponto de vista dos sujeitos, os personagens envolvidos nos processos educativos. 4) A consciência de que a subjetividade intervém no processo de pesquisa e que é preciso tomar medidas para controlá-la (Gatti \& André, 2011, p. 34).

Já a pesquisa de campo é utilizada para se obter informações sobre um determinado problema, para o qual se pretende alcançar uma possível resposta, ou uma hipótese e consiste em três estágios, quais sejam: a) pesquisa bibliográfica; b) escolha das técnicas para construção de dados e amostragem; c) estabelecimento das técnicas de registro e análise de dados (Marconi \& Lakatos, 2003). Dessa forma, realizamos, inicialmente, um levantamento bibliográfico sobre os conceitos que basearam o estudo, quais sejam a interdisciplinaridade, o currículo integrado e a formação humana integral. Nessa etapa, apoiamo-nos em autores como Moura (2012, 2013), Ciavatta (2014) e Ramos (2008). Segundo Gil (2002), quase todos os tipos de pesquisa envolvem o levantamento bibliográfico, pois serve como arcabouço teórico para o embasamento dos argumentos e, posteriormente, para nortear a análise dos resultados.

Em seguida, fizemos, ainda a partir de pesquisa bibliográfica, um estudo sobre o desenvolvimento de materiais didáticos, sob a perspectiva de Kaplún (2003), que estabelece três eixos temáticos para a construção de materiais educativos: o eixo conceitual; o eixo pedagógico e o eixo comunicacional, que detalharemos na próxima seção.

Visando à coleta dos dados que serviram de apoio direto na construção do PE, compondo parte essencial do eixo conceitual, na busca por uma espécie de diagnóstico do perfil dos sujeitos a quem o produto se destinou, realizamos um grupo focal com seis professores do Curso Técnico em Agroindústria Integrado ao Médio IFTM Campus Ituiutaba sobre a integração curricular, para a análise da prática docente e sua concepção, dúvidas e dificuldades sobre o tema.

O grupo focal é uma técnica que vem sendo mais utilizada a cada dia, em geral em pesquisas qualitativas. Os participantes recrutados devem apresentar características em comum, que os coloquem aptos para a discussão do problema social que é apresentado. No caso da presente pesquisa, todos os participantes eram docentes do Curso Técnico em Agroindústria Integrado ao Ensino Médio do Campus Ituiutaba. Outro ponto em comum foi o interesse de todos eles pela temática do currículo integrado e a sua experiência, em menor ou maior grau, com atividades interdisciplinares e práticas integradoras. A vivência com o tema é bastante interessante para o sucesso do grupo focal, para que sua participação esteja subsidiada por experiências reais (Gatti, 2005).

O grupo focal ocorreu pela plataforma Google Meet $\mathrm{e}$ foi mediado pela pesquisadora, acompanhada de sua orientadora. Teve a duração de $2 \mathrm{~h} 11$ min e os registros foram feitos por gravação da reunião remota, pela própria plataforma, e por anotações pessoais da pesquisadora, durante a interação do grupo. Para o tratamento e interpretação dos dados, procedemos uma análise qualitativa e buscamos nos aproximar da análise de conteúdo, de Lawrence Bardin (2016). De acordo com Minayo (1994), é possível destacar duas funções no uso da análise de conteúdo, quais sejam a verificação de uma hipótese ou questão e a descoberta daquilo que está por trás dos conteúdos manifestos. As duas funções podem ser complementares na prática e podem contribuir tanto com pesquisas quantitativas quanto com pesquisas de cunho qualitativo.

\section{Os Eixos Temáticos de Kaplún na Construção de um Produto Educacional Sob a Perspectiva da Formação Humana Integral}

A pesquisa que antecedeu o desenvolvimento do produto educacional que apresentamos neste texto retomou os conceitos de interdisciplinaridade, currículo integrado e formação humana integral, no âmbito do Ensino Médio Integrado (EMI). 
Dessa forma, baseamo-nos no ideário da formação dos sujeitos em suas múltiplas dimensões, visando a uma educação para a cidadania e para a superação da dicotomia 'trabalho manual' e 'trabalho intelectual' (Moura, 2012, 2013). Nessa perspectiva,

o ensino médio integrado pode ser um horizonte para uma formação que tenha como objetivo formar as pessoas em todas as dimensões da vida e superação de uma dualidade construída historicamente. Essa possibilidade precisa estar articulada com propostas de ensino ligadas a uma nova postura de encarar a formação que prepara para todas as dimensões da vida (Martins, et al., 2020, p. 15).

$\mathrm{Na}$ busca por essa formação, o currículo integrado se mostra como uma possibilidade de transpor a histórica e social dualidade escolar: a escola que forma líderes e a escola que forma mão de obra para o mercado de trabalho, uma vez que permite a integração da formação propedêutica com a formação técnica profissional (Ciavatta, 2014). Essa integração, segundo Ramos (2008), deve recorrer aos pressupostos da interdisciplinaridade, no sentido de evidenciar a unidade existente entre as disciplinas, indo de encontro à fragmentação disciplinar e em busca de uma compreensão global do conhecimento (Santomé, 1998).

O caráter interdisciplinar pode ser percebido em diversos níveis no ambiente escolar, desde o prescrito nos documentos oficiais, perpassando pelo inscrito - proposto pelas instituições escolares - até o escrito - sendo este relacionado à materialização da prática docente em sala de aula - (Fazenda, 2010). Sendo compreendida como articulação entre teorias e conceitos em constante diálogo,

A prática interdisciplinar poderá ser institucionalizada mediante uma estrutura curricular integrada por dispositivos curriculares como projetos, situação problemas ou módulos de trabalho coletivo, entre outros. No entanto, não basta institucionalizar é necessário buscar conhecer nas experiências formadoras da prática interdisciplinar, por exemplo, um pouco das nossas possibilidades, dificuldades e limites advindos da nossa formação acadêmica, entre outras questões [...] (Ferreira, 2010, p.17).

Segundo Ramos (2008), longe do entendimento da integração como somatória, superposição ou subordinação de um conhecimento a outro, o trabalho interdisciplinar vem na ideia da integração dos saberes, na perspectiva da totalidade. Essa dialogicidade pode se revelar nas práticas integradoras, a exemplo do projeto integrador, uma possibilidade presente na realidade em instituições de ensino médio em nosso país, na tentativa de construção de um currículo integrado (Henrique \& Nascimento, 2015). Nesse sentido, Ramos (2005) sugere um desenho do currículo integrado composto por quatro etapas:

1. Problematizar fenômenos - fatos e situações significativas e relevantes para compreendermos o mundo em que vivemos, bem como processos tecnológicos da área profissional para a qual se pretende formar [...]

2. Explicitar teorias e conceitos fundamentais para a compreensão do(s) objeto(s) estudado(s) nas múltiplas perspectivas em que foi problematizada e localizá-los nos respectivos campos da ciência (áreas do conhecimento, disciplinas científicas e/ou profissionais), identificando suas relações com outros conceitos do mesmo campo (disciplinaridade) e de campos distintos do saber (interdisciplinaridade) [...]

3. Situar os conceitos como conhecimentos de formação geral e específico, tendo como referência a base científica dos conceitos e sua apropriação tecnológica, social e cultural [...]

4. A partir dessa localização e das múltiplas relações, organizar os componentes curriculares e as práticas pedagógicas [...] (Ramos, 2005, p. 122-123).

Partindo desses conceitos, o PE foi pensado para proporcionar momentos de formação, discussão e trocas de experiências sobre o currículo integrado. O processo de planejamento, construção, desenvolvimento e avaliação do produto foi feito com base em Kaplún (2003), para quem um material educativo precisa ser algo que facilite uma experiência de ensinoaprendizagem. Tomando o objeto de estudo da pesquisa que norteou a construção do produto educacional aqui apresentado como elemento norteador para essa elaboração, a integração curricular no contexto da Educação Profissional e Tecnológica de Nível Médio do IFTM Campus Ituiutaba pôde ser apoiada pelo produto proposto, uma vez que visou colaborar para a prática dos 
professores e disseminar conhecimento sobre o tema para toda a comunidade escolar.

A intenção foi auxiliar os professores na materialização da integração curricular, no contexto do Ensino Médio Integrado (EMI) do IFTM Campus Ituiutaba. Dessa forma, pensamos um produto educacional a partir da concepção de Kaplún (2003), que estabelece três eixos temáticos para a construção de materiais educativos: o eixo conceitual; o eixo pedagógico e o eixo comunicacional. O primeiro diz respeito à

[...] escolha das ideias centrais abordadas pelo material, bem como o tema ou temas principais geradores de experiências de aprendizado. Para tanto, conhecer os debates em torno do tema e a opinião de autores sobre o assunto ajudará a compor o material educativo. É importante também conhecer os sujeitos a quem se destina o material para entender o que sabem, pensam, querem, imaginam e ignoram sobre o tema em questão e quais das suas necessidades poderiam ser respondidas pelo material (Leite, 2018, p. 334).

Para atender a esse eixo, várias etapas da pesquisa foram fundamentais, desde a bibliográfica até o levantamento de dados por entrevistas e grupo focal. Assim, pudemos desenvolver ideias acerca do tema selecionado, conhecer melhor o público envolvido na investigação e definir um ponto de partida, o que nos remete ao segundo eixo de Kaplún (2003), o pedagógico, que configura o articulador principal de um produto educacional.

Ele expressa o caminho que estamos convidando alguém a percorrer, quais pessoas estamos convidando e onde se encontram essas pessoas antes de partirmos. Kaplún (2003) sugere um itinerário pedagógico que contemple as concepções dos sujeitos; o confronto dessas ideias para mostrar suas possíveis causas; introdução, de modo gradual e acessível, de conceitos utilizados por teóricos da área; e também atividades que permitam a aplicação e a apropriação desses conceitos. Por meio do itinerário pedagógico estabelecemos onde o destinatário está em relação ao eixo conceitual proposto com a intenção de construirmos uma nova percepção sobre o tema (Leite, 2018, p. 334).

Ao entendermos, a partir da pesquisa feita, que a integração curricular ocorria ainda de maneira desarticulada institucionalmente e estava presente apenas a partir de iniciativas isoladas de alguns professores, definimos esse cenário como o ponto de partida em relação ao eixo conceitual. A construção e/ou uma afirmação da percepção sobre o tema se fazia bastante necessária e isso foi, portanto, o ponto de chegada por nós estabelecido, no sentido de propormos um produto educacional que pudesse auxiliar os professores na materialização do currículo integrado.

Para isso, iniciamos a etapa de construção do produto propriamente dito, no formato de um evento, que contribuísse para a discussão e para a formação continuada dos professores (e demais servidores do Campus) sobre o tema, o que nos coloca na dimensão do terceiro eixo de Kaplún (2003). "Eixo comunicacional: diz respeito ao formato, diagramação e linguagem empregada no material educativo. Esse eixo propõe que, pelo tipo de figura retórica ou poética sejam criados modos concretos de relação com os destinatários" (Leite, 2018, p. 334).

Isso posto, observamos que os três eixos temáticos que Kaplún (2003) considera cruciais para a elaboração de materiais educativos estão presentes na pesquisa. Passamos, nas linhas seguintes, à descrição detalhada dos passos para o desenvolvimento do PE e à discussão dos resultados observados.

\section{I Simpósio do Currículo Integrado IFTM Campus Ituiutaba: um Produto Educacional}

O grupo focal realizado para a coleta de dados teve início com a apresentação dos objetivos da atividade. Iniciamos, então, um debate sobre as (im)possibilidades da prática da integração curricular no Campus. Houve um consenso entre os participantes de que há, pelo menos entre alguns docentes, o interesse e a busca por atividades interdisciplinares e integradoras. No entanto, questões estruturais e organizacionais, em termos de instituição, ainda são fatores limitantes para a viabilização e sucesso dessas práticas. Essa informação foi ao encontro do que se descobriu a partir das entrevistas, reforçando essas barreiras 
e dificuldades.

Houve uma demanda urgente, por parte dos docentes presente no grupo focal, de tempos e espaços para a discussão do tema, como reuniões em que os professores se sentissem pertencentes ao debate sobre o currículo integrado e em que houvesse o sentimento de coletividade; momentos de formação e capacitação sobre a temática, pois, segundo os participantes, é necessário que todos saibam realmente o que é o currículo integrado, a formação humana integral que se busca com esse currículo e as especificidades do EMI.

Frente aos impasses supracitados pelos participantes do grupo focal em relação à prática do currículo integrado na instituição investigada, questionamos os participantes sobre qual produto educacional poderia contribuir para essa realidade e como conseguir a integração curricular em meio a essas contradições. A partir desses questionamentos, foi sugerido, pelos participantes, que esse tipo de iniciativa partisse dos próprios professores, que deveriam criar momentos de trocas de experiências e espaço de debate.

A ideia seria identificar essas pessoas dentro do Campus, para que pudessem formar um grupo de estudos ou um núcleo integrador, promovendo momentos de apresentação das diversas áreas, com o intuito de que os próprios professores conhecessem o trabalho de seus pares, bem como sua área de atuação e pudessem, assim, de maneira coletiva, visualizar possibilidades de articulação entre essas áreas, principalmente entre a área técnica e a de formação geral.

Contudo, essa ideia gerou também um argumento em contrapartida, no sentido de que as iniciativas para a viabilização do currículo integrado devessem partir da própria instituição, e não dos professores. Esse ponto havia sido mencionado também na etapa anterior da pesquisa, as entrevistas, quando alguns participantes colocaram a gestão escolar em primeiro plano, quando se falou em caminhos para a construção de um currículo integrado na prática. Nesse sentido, houve algumas sugestões: a revisão de ementas, a reorganização da estrutura escolar, na tentativa de facilitar o trabalho conjunto dos professores, a promoção de eventos, reuniões e espaços de discussão sobre o tema.

Em relação à materialização da integração, os participantes mencionaram a proposta de projetos de pesquisa e extensão, pois, pela sua natureza, permitem a integração de áreas e o trabalho coletivo dos professores. Sobre o foco do produto educacional, fruto desta pesquisa, foi unânime o fato de que este deveria ser o corpo docente do Campus, com o intuito de impactar positivamente suas práticas.

Além desses apontamentos, um dos participantes indicou que seria importante pensar em um produto que também orientasse os professores a como avaliar as atividades integradoras. Sendo a avaliação um desafio por si só, quando pensamos em atividades articuladas, envolvendo diferentes áreas, com a participação de mais de um professor, essa tarefa pode ser vista como algo bastante abstruso.

Ao término do grupo focal, a pesquisadora se reuniu com a orientadora e, em análise do que foi discutido no encontro, a realização de um evento foi entendida como o produto educacional que melhor atenderia aos anseios dos professores. Foi bastante perceptível a necessidade dos professores por momentos de debate, discussão, troca de experiência e formação sobre o tema investigado. O evento, podendo reunir palestra, roda de conversa, apresentações orais, construção coletiva de documentos e orientações, entre outros momentos de interação, pareceu atender, de maneira mais próxima, àquilo que foi apresentado como demanda pelos participantes do grupo focal.

Nesses moldes, optamos por desenvolver, como produto educacional, um simpósio, que denominamos 'I Simpósio do Currículo Integrado IFTM Campus Ituiutaba', realizado de maneira virtual ${ }^{1}$, tendo como público-alvo principal, os servidores do Campus Ituiutaba. Foram incluídos, além dos docentes, a equipe gestora e os servidores técnicos administrativos, pois

\footnotetext{
${ }^{1}$ Devido à situação de isolamento social e substituição das atividades acadêmicas presenciais por atividades remotas, em virtude da pandemia do novo coronavírus, que assolou o mundo a partir de março de 2020, todo o simpósio foi planejado para ocorrer de maneira virtual, desde a organização à execução do evento.
} 
entendemos que saber sobre as particularidades do EMI e o currículo integrado é importante para todos os sujeitos do ambiente escolar, sejam eles docentes ou não.

Iniciamos, então, a etapa de planejamento do evento e escrita do projeto, que foi apresentado às equipes gestora e pedagógica do Campus. Como objetivo geral do simpósio, elencamos a intenção de realizar um evento de formação e discussão sobre o currículo integrado. Para a delimitação dos objetivos específicos esperados para o evento, nos baseamos nos resultados obtidos após a análise do grupo focal. Dessa forma, elencamos os seguintes objetivos específicos: realizar palestra com professor externo convidado, sobre os caminhos para o currículo integrado no EMI dos IFs; realizar apresentações orais de docentes do Campus sobre projetos integradores e práticas interdisciplinares; realizar mesa redonda com professores externos, do ProfEPT, sobre o tema; promover a formação continuada dos servidores do Campus; possibilitar momentos de diálogo e troca de experiências sobre o currículo integrado e promover o debate participativo sobre o currículo integrado, dando subsídios para a sua prática pelos professores do Campus.

Após a aprovação do projeto pela gestão, passamos à fase de construção da comissão organizadora, por meio de portaria interna. Em seguida, iniciamos as reuniões para a divisão de atividades e organização do evento. As reuniões aconteceram por meio da plataforma Google Meet e, para facilitar a comunicação entre os membros da comissão, criamos um grupo no aplicativo de mensagens WhatsApp. Para melhor ilustrarmos as etapas de elaboração e validação do produto educacional, apresentamos o Quadro 1, a seguir.

Quadro 1. Etapas de elaboração do produto educacional.

\begin{tabular}{|c|c|}
\hline ETAPAS & DESCRIÇÃO DA ATIVIDADE \\
\hline Etapa 1 & Grupo focal com professores do curso participantes da pesquisa \\
\hline Etapa 2 & Encontros de discussão e planejamento, envolvendo a pesquisadora e sua orientadora \\
\hline Etapa 3 & Definição do produto educacional - Evento - e esboço de projeto \\
\hline Etapa 4 & Escrita do projeto do evento e apresentação para a equipe gestora \\
\hline Etapa 5 & Criação de portaria de comissão organizadora \\
\hline Etapa 6 & Reuniões de organização e planejamento \\
\hline Etapa 7 & Criação da arte e material de divulgação - banners, folder, posts para redes sociais etc. \\
\hline Etapa 8 & Divulgação do evento \\
\hline Etapa 9 & Apresentação e validação - Realização do evento \\
\hline Etapa 10 & Avaliação \\
\hline Etapa 11 & Publicação do produto educacional, após aprovação da banca examinadora, no repositório EduCapes \\
\hline
\end{tabular}

Fonte: Elaborado pelos autores (2021).

Uma das primeiras preocupações na organização do evento foi a seleção dos palestrantes. Considerando o tema a ser abordado, foram convidados professores e pesquisadores que tivessem amplo conhecimento sobre a integração curricular, a exemplo do professor doutor Dante Henrique Moura, que proferiu a palestra de abertura do evento. Os contatos foram realizados inicialmente por e-mail e por aplicativos de mensagens e oficializados por meio de cartas-convite emitidas pela Direção Geral do Campus.

Após o aceite dos palestrantes, realizamos a organização da programação do evento, com a distribuição das atividades e os respectivos horários. A programação contou com palestra, apresentações orais, mesa redonda e elaboração coletiva de um plano estratégico, conforme apresentamos no Quadro 2 abaixo. 
Quadro 2. Programação do I Simpósio do Currículo Integrado IFTM Campus Ituiutaba.

\begin{tabular}{|c|c|}
\hline $1^{\circ} \mathrm{Dia}$ & $2^{\circ} \mathrm{Dia}$ \\
\hline Manhã - 09:00 - 11:30 & Manhã - 09:00 - 11:30 \\
\hline $\begin{array}{ll}\text { - } & \text { Abertura do evento } \\
\text { - } & \text { Homenagem ao centenário de Paulo Freire } \\
\text { - } & \text { Palestra: Possibilidades de organização do currículo } \\
\text { no Ensino Médio Integrado }\end{array}$ & $\begin{array}{l}\text { - Mesa redonda: As bases da EPT e o Ensino Médio } \\
\text { Integrado: discussões sobre o currículo }\end{array}$ \\
\hline Tarde $-14: 00-17: 00$ & Tarde $-14: 00-17: 00$ \\
\hline $\begin{array}{l}\text { - Apresentações orais: Experiências e Propostas de } \\
\text { Projetos Integradores }\end{array}$ & $\begin{array}{l}\text { - } \\
\text { Palestra - Projetos Integradores: reflexões sobre } \\
\text { os documentos norteadores e o contexto da prática } \\
\text { - } \\
\text { - } \\
\text { Escrita coletiva: Plano estratégico } \\
\text { Encerramento }\end{array}$ \\
\hline
\end{tabular}

Fonte: Elaborado pelos autores (2021).

Feita a programação e a configuração do evento, entendemos que algumas atividades poderiam ser prestigiadas por um público externo, considerando a possibilidade de alcance dos meios utilizados para a transmissão. Dessa forma, observamos que tanto a palestra inicial quanto a mesa redonda eram potencialmente de grande interesse dos alunos do programa de mestrado do ProfETP em geral, devido à temática abordada. Já as atividades realizadas nas duas tardes do evento envolviam discussões internas ao Campus Ituiutaba, inviabilizando a presença de outro público.

A partir da programação, passamos ao estudo dos meios de execução. A escolha das plataformas de transmissão foi pensada para atender aos objetivos de cada atividade, além do tipo e número de público estimado. Para as atividades abertas também à comunidade externa, para as quais esperávamos um público maior de 100 pessoas (limite para as reuniões no Google Meet), optamos pelo YouTube, que comporta um número ilimitado de participantes. Para as atividades internas ao Campus, utilizamos o Google Meet, que permitiria maior interação entre os participantes e cujos links foram divulgados apenas entre esse público, por e-mail institucional e grupos de WhatsApp. Todo o trabalho de criação das salas virtuais e operacionalização das transmissões foi responsabilidade da equipe de Tecnologia da Informação do Campus, cujos servidores eram também membros da comissão organizadora do evento.

Devido à abrangência do público estimado para as atividades abertas ao público externo, tanto a palestra como a mesa redonda foram traduzidas, em sua totalidade, para a Língua Brasileira de Sinais (Libras), permitindo que fossem acessíveis ao público surdo. Para isso, contamos com o apoio da intérprete de Libras do Campus e de mais dois intérpretes do IF Goiano, que foram contatados pela coordenação do ProfEPT dessa instituição. As atividades internas não demandaram tradução para Libras, pois o Campus não apresentava, no momento, nenhum servidor surdo.

Durante as reuniões de planejamento da comissão, definimos as pessoas responsáveis por cada atividade. Dessa forma, escolhemos os mestres de cerimônia, mediadores e os moderadores do chat. Criamos um documento no Google Drive com as atribuições da comissão, para que todos pudessem ter acesso e consultá-lo sempre que necessário. O Google Docs foi também a ferramenta escolhida para ser a comunicação entre os mediadores da palestra e da mesa redonda e os responsáveis pela seleção das perguntas aos palestrantes, uma vez que esse recurso permitiria que as pessoas com quem o documento foi compartilhado pudessem acessá-lo e editá-lo simultaneamente. Dessa forma, o documento era alimentado em tempo real com as perguntas postadas no chat pelo público e que seriam feitas aos palestrantes, pelos mediadores, ao final de cada fala.

Definimos, também, a estratégia de divulgação interna e externa. Utilizamos alguns softwares para a criação da arte do evento e de todo o material de divulgação, como o Canva ${ }^{2}$ e o Heyzine ${ }^{3}$. Com o auxílio dessas ferramentas, elaboramos banners,

2 Plataforma de criação de conteúdo digital disponível em https://www.canva.com/.

3 Plataforma utilizada para converter documentos no formato PDF para flipbooks, disponível em https://heyzine.com/. 
folder e posts para redes sociais. Todo o trabalho de criação e montagem das peças de divulgação foi feito pela própria pesquisadora com o uso de equipamento próprio.

A divulgação aos servidores do IFTM Campus Ituiutaba ocorreu por meio de e-mail institucional, pelo aplicativo de mensagens instantâneas WhatsApp e pelo site institucional, com o link das inscrições. Para os servidores, foram utilizadas todas as peças de divulgação criadas, sobretudo o folder. A divulgação externa do simpósio aconteceu por redes sociais, nas páginas do Facebook e Instagram destinadas a turmas do ProfEPT de diversas Instituições Associadas, além de mensagens enviadas por aplicativos de mensagens. Para essas redes, foram utilizados o banner geral e banners específicos para a divulgação da palestra e da mesa redonda, uma vez que essas atividades eram destinadas a esse público. As Figuras 1 e 2 trazem exemplos da divulgação.

Figura 1. Exemplo de divulgação externa.

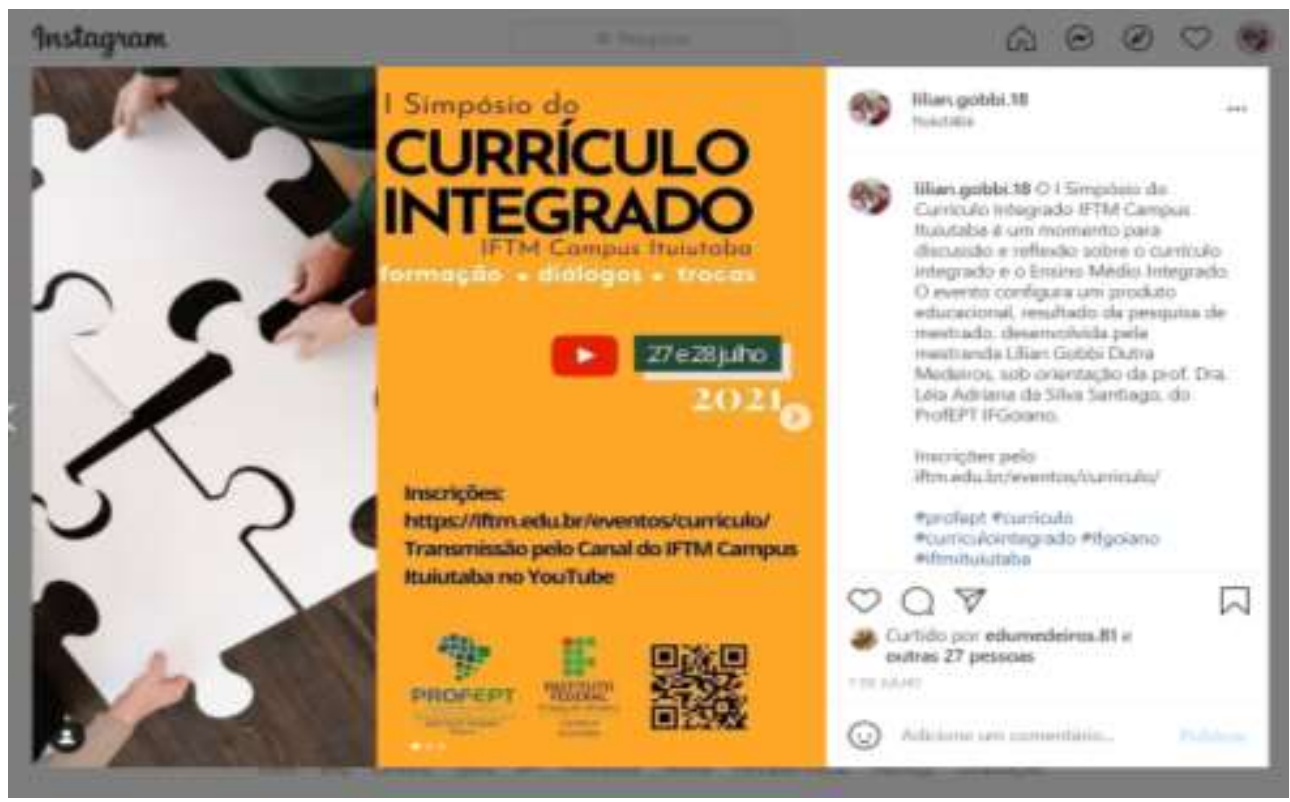

Fonte: Medeiros (2021).

Figura 2. Exemplo de post para divulgação em grupos de WhatsApp.

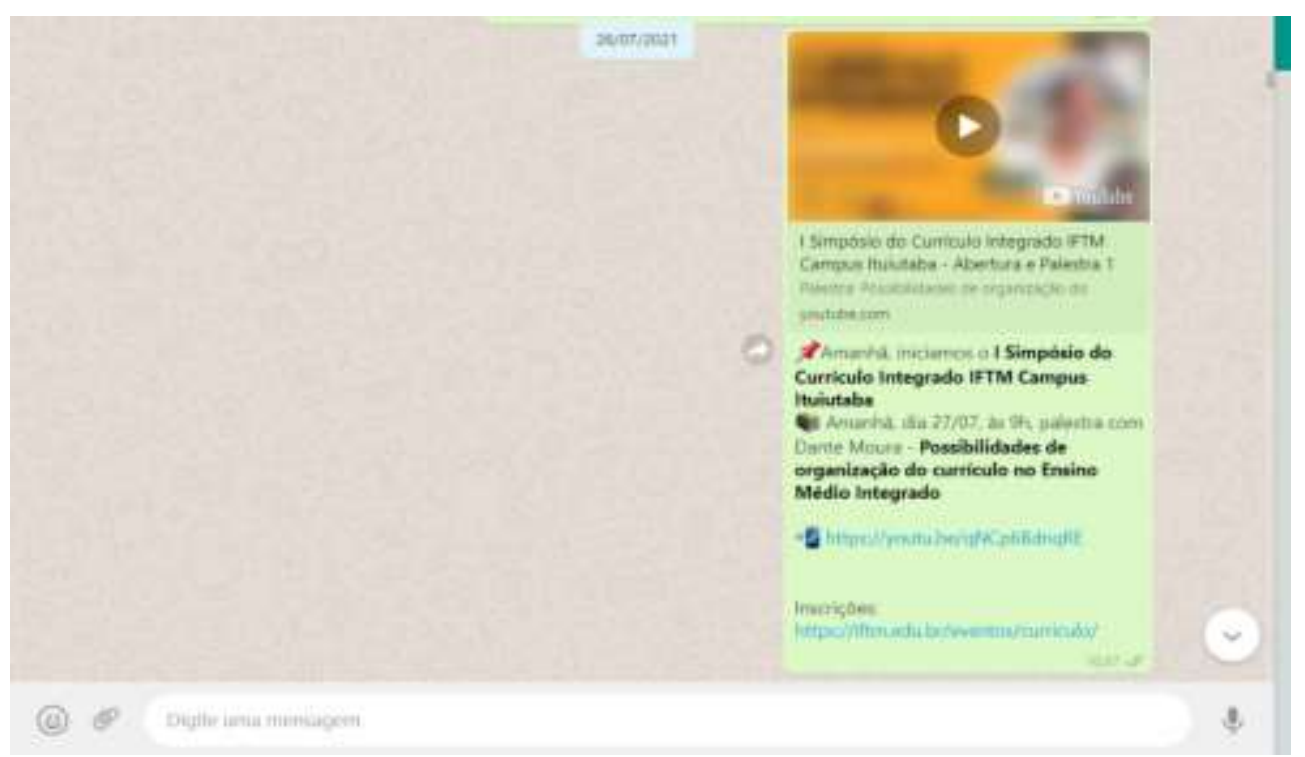

Fonte: Medeiros (2021). 
As inscrições foram realizadas pelo site $e^{4}$ da instituição, após o cadastro do evento no módulo Eventos Institucionais, que é uma das funcionalidades do sistema utilizado pelo IFTM. A partir desse módulo, foi possível gerar a página das inscrições, credenciamento digital, listas de presença (e o link para que cada um pudesse registrar a sua presença) e emissão dos certificados. Após ampla divulgação, tivemos um total de 177 inscrições, entre público interno e comunidade externa.

O evento aconteceu nos dias 27 e 28 de julho do ano de 2021 e teve uma boa participação do público. A palestra ${ }^{5}$ que abriu o evento, proferida pelo professor Dante Henrique Moura, do Instituto Federal do Rio Grande do Norte (IFRN), um dos principais nomes do nosso referencial teórico, registrou até 107 pessoas assistindo ao vivo e o vídeo contabiliza 497 visualizações até a presente data, sendo que as atividades realizadas pelo YouTube permanecem listadas entre os vídeos no canal do IFTM Campus Ituiutaba, podendo ser assistidas por qualquer pessoa conectada à rede.

Na sequência das atividades do primeiro dia de evento, na parte da tarde, houve a realização de apresentações orais, na atividade que denominamos 'Experiências e propostas de projetos integradores'. Essa etapa foi realizada pelo Google Meet e tivemos até 67 pessoas presentes na sala, sendo todos servidores do Campus. Os professores que realizaram as apresentações orais foram convidados, por e-mail institucional, a apresentarem atividades integradores que tivessem realizado ou planejado com seus alunos. Ao todo, tivemos a inscrição de quatro trabalhos, sendo que foram destinados 15 minutos para cada apresentação, seguida de um debate de 20 minutos.

A mesa redonda ${ }^{6}$, realizada na manhã do dia 28 de julho de 2021, contou com a participação de três professores convidados: professor Francisco das Chagas, do IFRN, professor Marco Antônio de Carvalho, professor do ProfEPT do IF Goiano e professora Lívia Zanier, do IFTM. Os palestrantes realizaram suas falas referentes ao tema proposto e, ao final de suas apresentações, responderam perguntas do público postadas no chat. A transmissão ao vivo foi assistida por até 96 pessoas e o vídeo postado no canal do YouTube conta, até a presente data, com 436 visualizações.

Na tarde do dia 28 de julho, contamos com até 55 pessoas presentes na sala do Google Meet para a realização de duas atividades. A primeira foi a palestra 'Projetos Integradores: reflexões sobre os documentos norteadores e o contexto da prática', que gerou bastante engajamento dos presentes, que direcionaram várias perguntas ao palestrante ao final de sua apresentação. $\mathrm{O}$ segundo momento visou à escrita colaborativa, pelos servidores, de um plano estratégico para as ações sobre o currículo integrado no Campus. Desse momento, destacamos a criação de um Grupo de Trabalho (GT) para dar continuidade às atividades sobre o currículo integrado no Campus.

Para operacionalizar essa escrita, utilizamos o recurso do Google Docs, abrindo um documento para ser alimentando durante as falas dos participantes, que também poderiam acessá-lo e editá-lo concomitantemente à sua elaboração. A tela do documento também foi compartilhada na sala do Google Meet, para que todos pudessem acompanhar esse processo de construção. O objetivo dessa atividade foi traçar caminhos para investigações, trabalhos, estudos e ações diversas sobre o currículo integrado no âmbito do IFTM Campus Ituiutaba.

Após a realização do evento, passamos à etapa da avaliação do produto educacional. Para isso, elaboramos um formulário utilizando o Google Forms, com perguntas abertas e fechadas. Em obediência ao projeto que foi aprovado pelo CEP, colhemos respostas apenas dos professores participantes da pesquisa. Assim, enviamos a avaliação aos 12 docentes que foram entrevistados e que participaram do grupo focal, na etapa de coleta de dados, sendo um deles o coordenador do curso.

Obtivemos, no total, 8 respostas. O evento foi avaliado de maneira bastante positiva, considerando que todos os respondentes afirmaram que o evento trouxe informações/conhecimentos novos sobre o tema do currículo integrado. Outra resposta unânime foi a de que os temas abordados no simpósio e as discussões apresentadas podem ajudar, de alguma forma, no

\footnotetext{
${ }^{4} \mathrm{https}: / /$ iftm.edu.br/eventos/curriculo/

${ }^{5} \mathrm{O}$ vídeo da palestra encontra-se disponível em https://www.youtube.com/watch?v=qNCp6BdnqRE\&t=2959s.

${ }^{6} \mathrm{O}$ vídeo da mesa redonda encontra-se disponível em https://www.youtube.com/watch?v=PoG9aReRQL0.
} 
trabalho/estudo dos participantes. Assim, pensamos que o produto educacional cumpriu o objetivo proposto, pois as respostas obtidas dão indícios de que o evento, de fato, proporcionou momentos de formação e discussão sobre o currículo integrado.

Para uma avaliação mais detalhada do produto, lançamos mão de uma questão fechada, em que o respondente deveria avaliar o evento como 'fraco', 'razoável', 'bom' ou 'excelente' para cada um dos seguintes elementos: organização, projeto visual, divulgação, programação/temas abordados, conhecimento dos palestrantes sobre o tema, adequação da carga horária para as atividades e uso dos recursos/tecnologias. A avaliação, segundo esses quesitos, também foi bastante positiva, conforme mostra o Gráfico 1 abaixo.

Gráfico 1. Avaliação do evento por categoria.

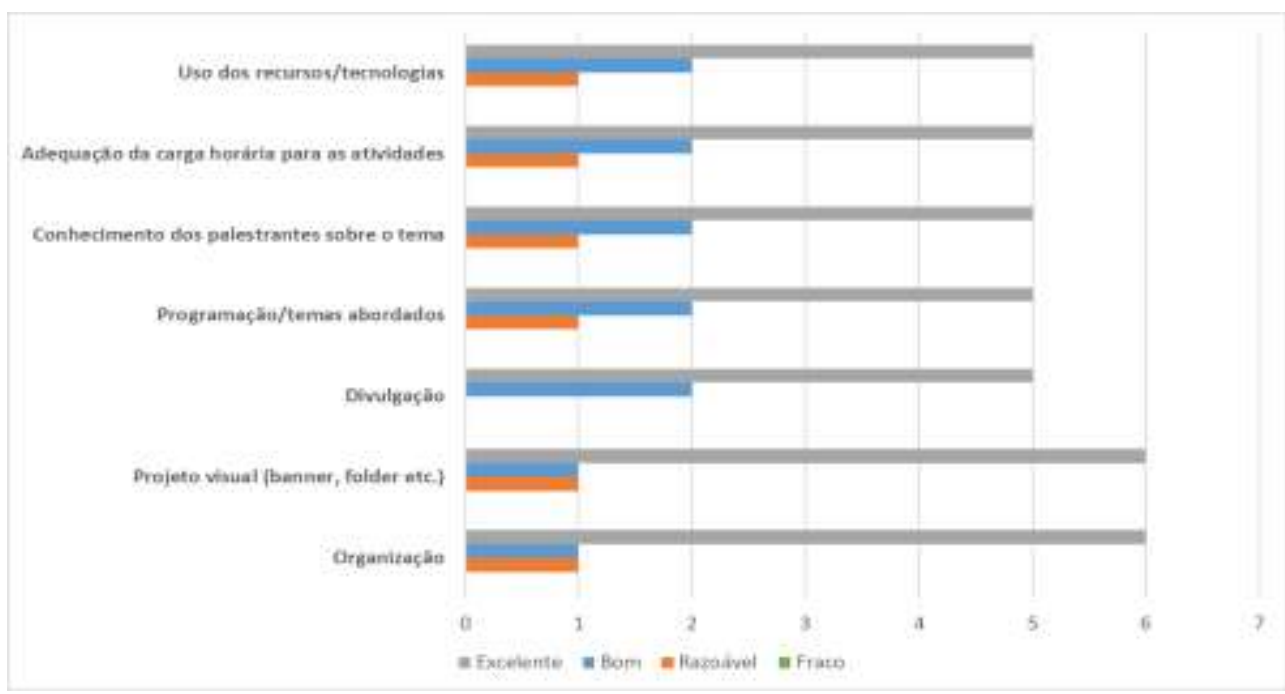

Fonte: Elaborado pelos autores, com base nos dados da pesquisa (2021).

Conforme é possível observar pela Gráfico 1 acima, nenhum participante classificou como 'fracos' os elementos colocados sob avaliação e o conceito 'excelente’ foi predominante em todos os quesitos, tendo sido atribuído em 6 respostas para os itens 'organização' e 'projeto visual' e em 5 para os demais itens.

Uma outra pergunta colocada foi: 'Comente sobre as informações/conhecimentos que você adquiriu no evento'. Para essa questão, obtivemos as respostas apresentadas abaixo. Para a identificação das falas, faremos uso da letra R, seguida de um numeral, representando cada um dos respondentes.

Achei interessante a apresentação da professora Livia, trazendo sua experiência com o paradigma da aprendizagem. Normalmente, as apresentações ficam no campo do "teórico". Nesse sentido, o Simpósio ultrapassou essa abordagem, mostrando possibilidades na prática. Cito aqui a professora Lívia, mas é válido também destacar o projeto "Corpo" que também mostrou as possibilidades de aplicação prática $(R 1,2021)$.

A diferença entre unidade curricular e disciplina foi uma delas (R2, 2021).

Reflexões e provocações no processo da busca de um currículo integrado no EMI (R3, 2021).

Pensar um currículo integrado e integrador, em especial no EPT, a partir de sua gênese e de sua episteme é fundamental para que possamos pensá-lo também como prática. A partir dessa constatação, as abordagens e provocações suscitadas pelos palestrantes foram muito ricas no sentido de nós fazerem perceber, entender ou refletir sobre conceitos e ideias que permeiam o tema e que, em muitos casos, a mim, escapavam (R4, 2021).

Muito produtivo e necessário para o aperfeiçoamento do currículo integrado (R5, 2021). 
Tive a oportunidade de adquirir uma bagagem riquíssima de novos conhecimentos sobre os fundamentos da EPT, da legislação pertinente ao EMI, entre outros (R6, 2021).

Conhecimento sobre formas de trabalho integrado em outras instituições, pois não tenho muita proximidade com este formato de fazer docente (R7, 2021).

É importante perceber, pelas falas apresentadas acima, que o evento se mostrou como um momento de aprendizado, de formação continuada, uma vez que a aquisição de novos conhecimentos e conceitos sobre o tema foi mencionada, como notamos nas falas de R2, R4, R6 e R7.

Ainda, a possibilidade de visualizar a integração curricular na prática, que foi uma de nossas preocupações durante o planejamento do simpósio, se fez presente na fala de R1, por exemplo. Consideramos esse um importante ponto a ser observado, pois o currículo integrado não deve permanecer no plano do prescrito, devendo ir além do que está previsto nos documentos oficiais ou nos conceitos teóricos. É preciso colocá-lo em prática e, pelos resultados obtidos, podemos considerar que o produto educacional aqui apresentado contribuiu para que os docentes pudessem entender melhor esse processo entre teoria e prática.

Para os participantes que afirmaram que o evento poderia auxiliá-los em seu trabalho/estudo, a seguinte pergunta foi feita: 'Como o evento pode te ajudar no seu trabalho/estudo?'. As respostas observadas foram:

Abriu um leque de possibilidades para o trabalho integrado, mostrando propostas bem sucedidas (R1, 2021).

A repensar e colocar em prática a interação com outras unidades curriculares (R2, 2021).

A compreender e desenvolver atividades que condiz com EMI (R3, 2021).

Foram suscitadas questões e possibilidades de atuação, as quais eu não havia pensado, que, acredito, poderão me direcionar de forma mais assertiva na construção de projetos e planos de ensino mais integrados (R4, 2021).

Discuto currículo integrado no Doutorado (R5, 2021).

O evento pode ajudar-me no trabalho em sala de aula, promovendo atividades/projetos envolvendo a Integração Curricular (R6, 2021).

Talvez me fazer aproximar um pouco mais deste formato docente, pois não estou acostumada com ele e confesso que tenho uma certa resistência a respeito $(R 7,2021)$.

Trazendo experiências, conceitos e diretrizes sobre o currículo integrado (R8, 2021).

Conforme é possível apreender das respostas acima, nenhum professor que participou da avaliação se isentou de responder a essa pergunta, que não era de resposta obrigatória. Dessa forma, entendemos que o evento tenha trazido benefícios a todos, mesmo que em menor ou maior grau, inclusive para a quebra de paradigmas em relação ao currículo integrado, como vemos na resposta de R7.

A última questão colocada foi ' $\mathrm{O}$ que faltou, na sua opinião, em relação aos(às) conhecimentos/informações contidos(as) no evento?'. Para essa pergunta, não obtivemos nenhuma resposta. Esse fato nos indica que o evento, de forma geral, atendeu às expectativas dos participantes e não deixou grandes lacunas em relação ao que ele se propunha. Por fim, disponibilizamos um espaço para comentário gerais e recebemos elogios e sugestões, conforme mostramos abaixo.

De maneira geral, o evento foi muito bom. Acredito que em um próximo Simpósio, possam ser convidados professores de outras instituições com experiência de currículo integrado, tal como foi a apresentação da professora Lívia (Rl, 2021).

O evento foi maravilhoso. Aprendi muito sobre as concepções e elaborações de um currículo integrado (R3, 2021). 
O evento abriu novas portas para que possamos, de fato, buscar uma integração de nossos currículos de forma endógena e não apenas "arbitrária" e pro forma como está descrita nos PPCs. É fundamental que ele seja apenas o primeiro de uma série de momentos que se seguirão $(R 4,2021)$.

Muito bom (R5, 2021).

Evento importantíssimo no atual cenário em que vivemos. Oportunidade de revermos nossos conceitos e nossa prática, em vistas de uma possível renovação no modo como a escola pode exercer com excelência sua função (R6, 2021).

A importância dada à prática do currículo integrado mais uma vez se revela na fala de R1, além de observarmos já um desejo dos participantes por mais momentos como o que tivemos no simpósio. Isso se percebe, por exemplo, nas falas de R1, R4 e R6, que não colocam a discussão como encerrada, mas como portas que se abriram para a revisão de conceitos e da prática docente e de uma renovação dos moldes que baseiam a integração curricular hoje no Campus analisado.

Feita a análise das respostas coletadas na avaliação do evento, podemos dizer que a realização do simpósio trouxe benefícios à comunidade acadêmica, que participou de momentos de formação, discussão e troca de experiências práticas sobre o currículo integrado. Percebemos que houve a aceitação dos participantes, uma vez que não recebemos nenhum tipo de crítica ou comentário que desabonasse o produto educacional desenvolvido.

\section{Considerações Finais}

O presente artigo objetivou apresentar os passos para o planejamento, aplicação e a avaliação de um PE, aplicado no Instituto Federal do Triângulo Mineiro (IFTM) - Campus Ituiutaba e que foi fruto de uma pesquisa no programa do Mestrado Profissional em Educação Profissional e Tecnológica do Instituto Federal de Educação, Ciência e Tecnologia Goiano.

Sob a perspectiva de Kaplún (2003), o PE foi desenvolvido seguindo os eixos conceitual, pedagógico e o comunicacional. A intenção foi auxiliar os professores na materialização da integração curricular, sobretudo no cumprimento da exigência prevista no PPC no curso observado nesta pesquisa, referente à Prática Profissional Integrada.

O evento se mostrou inovador e pioneiro no Campus, mas não único, uma vez que as avaliações feitas e os comentários realizados ao longo das atividades do simpósio indicam o desejo de toda a comunidade escolar para outros momentos como esse, outros eventos e propostas. O GT criado ao final do evento demonstra essa necessidade e disponibilidade, sobretudo dos servidores envolvidos diretamente nele, de dar continuidade ao que propusemos para esses dois dias.

O Campus Ituiutaba encerrará o primeiro ciclo de turmas dentro de um novo PPC no prazo de aproximadamente um ano e uma discussão se faz necessária: no que avançamos, no que esbarramos, quais as nossas percepções, quais as percepções dos alunos, como podemos avançar em relação ao que está posto? Sendo esse documento constantemente retomado nas participações dos professores, isso revela que é um tema de estudo necessário, que ainda há muita dúvida e inquietação a respeito do que está prescrito. Acreditamos que o GT criado possa contribuir bastante para esse avanço, dentro das ações propostas, sendo uma delas, e talvez a primordial, o estudo dos resultados desse novo PPC. O simpósio, nesse sentido, pareceu ser um momento de reafirmar essas necessidades e clarear os caminhos possíveis para essas discussões. Dessa forma, fazemos a interpretação de que o produto educacional tenha cumprido o seu papel e colaborado com subsídios para práticas integradoras no Campus Ituiutaba.

Como propostas para novas pesquisas, acreditamos na necessidade de uma investigação, conforme mencionamos anteriormente, sobre os resultados do novo PPC, levando em conta as percepções dos alunos em relação às práticas integradoras realizadas. Ainda, pensamos que seja importante uma pesquisa sobre os impactos do produto educacional aqui apresentado nas práticas futuras dos professores, na tentativa de entender os desdobramentos do simpósio e caminhar para outras edições do evento. 


\section{Referências}

Bardin, L (2016). Análise de conteúdo. Edições 70.

Capes - Coordenação de Aperfeiçoamento de Pessoal de Nível Superior. (2019). Portaria no 60, de 20 de março de 2019. Dispõe sobre o mestrado e doutorado profissionais, no âmbito da Coordenação de Aperfeiçoamento de Pessoal de Nível Superior - Capes. Brasília, DF: Diário Oficial da União. https://www.in.gov.br/web/guest/materia/-/asset_publisher/Kujrw0TZC2Mb/content/id/68157853/do1-2019-03-22-portaria-n-60-de-20-de-marco-de-201968157790 .

Ciavatta, M. (2014). Ensino Integrado, a Politecnia e a Educação Omnilateral: Por que lutamos? Trabalho \& Educação, 23(1), 187-205. https://periodicos.ufmg.br/index.php/trabedu/article/view/9303/6679.

Fazenda. I. C. (2012). Desafios e perspectivas do trabalho interdisciplinar no Ensino Fundamental. Contribuições das pesquisas sobre Interdisciplinaridade no Brasil: O reconhecimento de um percurso. In: A. I. L. F. Dalben, et al. XV ENDIPE - Encontro Nacional de Didática e Prática de Ensino. Convergências e tensões no campo da formação e do trabalho docente: políticas e práticas educacionais. Belo Horizonte: Autêntica.

Ferreira, N. R. S. (2012). Currículo: espaço interdisciplinar de experiências formadoras do professor da escola de educação básica. Interdisciplinaridade, 1(0), https://revistas.pucsp.br/index.php/interdisciplinaridade/article/view/16141.

Freire, P., \& Faundez, A. (1985). Por uma pedagogia da pergunta. (3a ed.), Paz e Terra.

Gatti, B. A., \& André, M. (2011). A relevância dos métodos de pesquisa qualitativa em educação no Brasil. In: W. Weller; N. Pfaff (Orgs.). Metodologias da pesquisa qualitativa em Educação:Teoria e prática. (3a ed.), (pp. 29-38). Vozes.

Gatti, B. A. (2005). Grupo focal na pesquisa em ciências sociais e humanas. Líber Livro.

Gil, A. C. (2002). Como Elaborar Projetos de Pesquisa. (4a ed.), Atlas.

Henrique, A.L.S., \& Nascimento, J. M. (2015). Sobre Práticas Integradoras: Um Estudo de Ações Pedagógicas na Educação Básica. Revista Holos, 4(31), http://www2.ifrn.edu.br/ojs/index.php/HOLOS/article/view/3188/1127.

Kaplún, G. (2003). Material educativo: a experiência de aprendizado. Comunicação \& Educação, (27), 46-60. https://www.revistas.usp.br/comueduc/article/view/37491. doi: 10.11606/issn.2316-9125.v0i27p46-60.

Leite, P. de S. C. (2018). Produtos Educacionais em Mestrados Profissionais na Área de Ensino: Uma proposta de avaliação coletiva de materiais educativos. $7^{\circ}$ Congresso Ibero-Americano em Investigação Qualitativa. https://proceedings.ciaiq.org/index.php/ciaiq2018/article/view/1656.

Marconi, M. A., \& Lakatos, E. M. (2003). Fundamentos de metodologia científica. (5a ed.), Atlas.

Martins, W. C., Lima, P. F. R., \& Freire, L. B. de O. (2020). A Interdisciplinaridade no Ensino Médio Integrado à Educação Profissional. Research, Society and Development, 9(1), https://rsdjournal.org/index.php/rsd/article/view/1634.

Minayo, M. C. S. (1994). Ciência, técnica e arte: o desafio da pesquisa social. In: M. C. S. Minayo (Org.). Pesquisa social:Teoria, método e criatividade. (18a ed.), (pp. 9-29). Vozes.

Moura, D. H. (2012). A organização curricular do Ensino Médio Integrado a partir do eixo estruturante: Trabalho, ciência, tecnologia e cultura. Labor, Fortaleza, 1(7). http://www.periodicos.ufc.br/labor/article/view/6702.

Moura, D. H. (2013). Ensino Médio Integrado: subsunção aos interesses do capital ou travessia para a formação humana integral? Educação e Pesquisa, São Paulo, 39(3), 705-720. http://www.scielo.br/scielo.php?script=sci_arttext\&pid=S1517-97022013000300010\&lng=en\&nrm=iso.

Ramos, M. (2008). Concepção do Ensino Médio Integrado. Secretaria de Educação do Estado do Paraná, Paraná, 1-30. https://tecnicadmiwj.files.wordpress.com/2008/09/texto-concepcao-do-ensino-medio-integrado-marise-ramos1.pdf.

Ramos, M. N. (2005). Possibilidades e desafios na organização do currículo integrado. In: G. Frigotto, M. Ciavatta \& M. Ramos (Orgs.). Ensino Médio Integrado: Concepções e contradições. (pp. 106-127). São Paulo: Cortez.

Rizzatti, I. M. R., Mendonça, A. P., Mattos, F., Roças, G., Silva, M. A. B. V. da, Cavalcanti, R. J. de S., \& Oliveira, R. R. de. (2020). Os produtos e processos educacionais dos programas de pós-graduação profissionais: Proposições de um grupo de colaboradores. Actio: Educação em Ciências, Curitiba, 5(2), https://periodicos.utfpr.edu.br/actio/article/view/12657.

Santomé, J. T. (1998). Globalização e interdisciplinaridade: O currículo integrado. Porto Alegre: Editora Artes Médicas Sul Ltda.

Soares, G. de O., Tamiosso, R. T., Santos, P. A. dos, Ritter, D., \& Canto-Dorow, T. S. do. (2021). Desenvolvimento de um produto educacional interdisciplinar: Sequências didáticas para além da sala de aula. Research, Society and Development, 10(2), https://doi.org/10.33448/rsd-v10i2.12290. 